\title{
MINI-REVIEW
}

\section{Functional Role of miRNAs in the Progression of Breast Ductal Carcinoma in Situ}

\author{
Bethany N. Hannafon and Wei-Qun Ding
}

From the Department of Pathology, University of Oklahoma Health Sciences Center, Oklahoma City, Oklahoma

\author{
Accepted for publication \\ June 15, 2018. \\ Address correspondence to \\ Bethany N. Hannafon, Ph.D., \\ Department of Pathology, Uni- \\ versity of Oklahoma Health \\ Sciences Center, 975 NE 10th \\ St., BRC 411A, Oklahoma \\ City, OK 73104. E-mail: \\ bethany-hannafon@ouhsc.edu.
}

\begin{abstract}
miRNAs are small RNAs that influence gene expression by targeting mRNAs. Depending on the function of their target genes, miRNAs may regulate the expression of oncogenes and tumor suppressors, thereby contributing to the promotion or inhibition of tumor progression. Ductal carcinoma in situ (DCIS), although often diagnosed as breast cancer, is a potential precursor to invasive ductal carcinoma. Many of the genetic events required for the invasive progression of DCIS occur at the preinvasive stage, and these events include changes in the expression of miRNAs. Aberrant expression of miRNAs can influence specific oncogenic or tumor-suppressive pathways required for breast cancer progression. miRNAs in DCIS have been shown to influence hormone signaling, cell-cell adhesion, epithelial-to-mesenchymal transition, transforming growth factor $\beta$ signaling, maintenance of cancer stem cells, and modulation of the extracellular matrix. Additionally, extracellular DCIS miRNAs, such as those found in exosomes, may promote invasive progression by modifying the tumor microenvironment. Here, we review the miRNAs that have been identified in DCIS and how they may contribute to the progression to invasive disease. We also touch on the current state of miRNA therapy development, including the current challenges, and discuss the key future perspectives for research into miRNA function for the purpose of miRNA therapy development for DCIS. (Am J Pathol 2019, 189: 966-974; https://doi.org/10.1016/j.ajpath.2018.06.025)
\end{abstract}

In the United States, it is estimated that of every eight women, one will be diagnosed with breast cancer. Of those women, about $20 \%$ will be diagnosed with the precursor to breast cancer, called ductal carcinoma in situ (DCIS) (https://www. cancer.org/research/cancer-facts-statistics/breast-cancerfacts-figures.html, last accessed June 5, 2018). DCIS is defined as an abnormal growth of cells that resemble cancer on pathologic examination but are retained within the ducts of the mammary gland; DCIS is therefore considered a benign lesion. Importantly, a woman diagnosed with DCIS is up to 10-fold more likely to later develop invasive ductal carcinoma (IDC). ${ }^{1}$ However, in about half of these women, this precursor lesion will not progress to IDC, even if untreated. ${ }^{2}$ This clinical conundrum may lead the oncologist to err on the side of caution, and many women undergo aggressive, and perhaps unnecessary, clinical treatments as though they have been diagnosed with IDC. Therefore, a better understanding of the biology of DCIS progression to IDC is crucial and necessary to identify those that will progress to IDC versus those that will not. This information will provide the crucial missing link for the proper clinical management of DCIS.

Although breast cancer is referred to as a single disease, at least four major molecular subtypes have been identified through gene-expression profiling. ${ }^{3,4}$ These subtypes include luminal A, luminal B, triple negative, and human epidermal growth factor receptor (HER)-2 enriched. Subtyping in the clinical setting is typically approximated by histologic examination of the elevated or reduced levels of certain biomarkers, including the estrogen receptor (ER), progesterone

Supported by National Institute of General Medical Sciences grant U54GM104938 (W.-Q.D.), the Presbyterian Health Foundation (W.-Q.D.), and Oklahoma Center for the Advancement of Science and Technology grant HR17-052 (B.N.H.).

Disclosures: None declared.

This article is part of a review series on Ductal Carcinoma in Situ-Discerning Aggressive versus Benign Disease Using Molecular Features. 
receptor (PR), HER2, and the proliferation marker Ki-67. These major subtypes have also been observed in DCIS, although at different frequencies, with $49 \%$ identified as luminal A (ER ${ }^{+}, \mathrm{Ki}-67$ low $) ; 8.7 \%$, as luminal $\mathrm{B}\left(\mathrm{ER}^{+}, \mathrm{PR}^{+}\right.$, $\mathrm{Ki}-67$ high); $7 \%$, as triple negative $\left(\mathrm{ER}^{-}, \mathrm{PR}^{-}, \mathrm{HER}^{-}\right)$; and $16 \%$, as HER2 enriched $\left(\mathrm{ER}^{-}, \mathrm{PR}^{-}, \mathrm{HER} 2^{+}\right){ }^{5,6}$ Although these markers are useful for categorizing DCIS, they have limited prognostic value in patients. ${ }^{6}$

To better understand the genetic events that may drive DCIS progression to invasive disease and to identify the biomarkers of progression, researchers have examined the cellular and molecular changes present in DCIS that may characterize the transition of DCIS to IDC. Despite these efforts, few prognostic markers have been discovered. ${ }^{7}$ These gene- and expression-profiling studies have found that the genetic characteristics of DCIS are highly similar to those of IDC, especially in patients with synchronous DCIS, ${ }^{8-13}$ with most changes occurring in the transition of normal epithelial cells to DCIS. ${ }^{14-17}$ Various theoretical models have been proposed for the initial development and invasive progression of DCIS, based on these studies. ${ }^{18}$ Mutations common to both IDC and DCIS have been identified in genes that may contribute to invasive progression, with TP53 (35\% IDC, 30\% DCIS), PIK3CA (34\% IDC, 55\% DCIS), and GATA3 (9\% IDC, 27\% DCIS) being the most frequently mutated. ${ }^{19-22}$ However, the main drivers of breast cancer progression remain undefined and may be dependent on the intrinsic subtype. Geneexpression patterns in DCIS and IDC vary across the intrinsic subtypes, with luminal tumors largely affected by differential expression of genes in the cell-adhesion and extracellular-matrix pathways, whereas HER2 ${ }^{+}$tumors are enriched for cell cycle-regulation pathways, and triplenegative tumors are mainly affected by genes involved in the immune response. ${ }^{23}$

\section{miRNA Biogenesis and Role in Breast Cancer}

miRNAs are a class of small regulatory RNAs that function by binding in a sequence-specific manner to the $3^{\prime}$ untranslated region of an mRNA and directing post-transcriptional repression. The biogenesis of miRNAs begins with transcription from a miRNA gene by RNA polymerase II into a primary miRNA. The primary miRNAs are known to form a hairpin loop by the binding of complementary regions. The end of the hairpin is then recognized and processed by the endonuclease Drosha and DiGeorge syndrome chromosome region protein 8 into a 60-nucleotide stem-loop structure called a pre-miRNA, also known as the precursor miRNA. The pre-miRNA is then exported out of the nucleus via exportin 5 and guanosine- $5^{\prime}$ triphosphate-binding Ras-related nuclear protein, where it is further processed by Dicer into the mature miRNA. The mature miRNA is loaded into an Argonaute protein with assistance from other chaperone proteins in a complex known as the RNAinduced silencing complex. The RNA-induced silencing complex -associated miRNA is then guided by the seed region

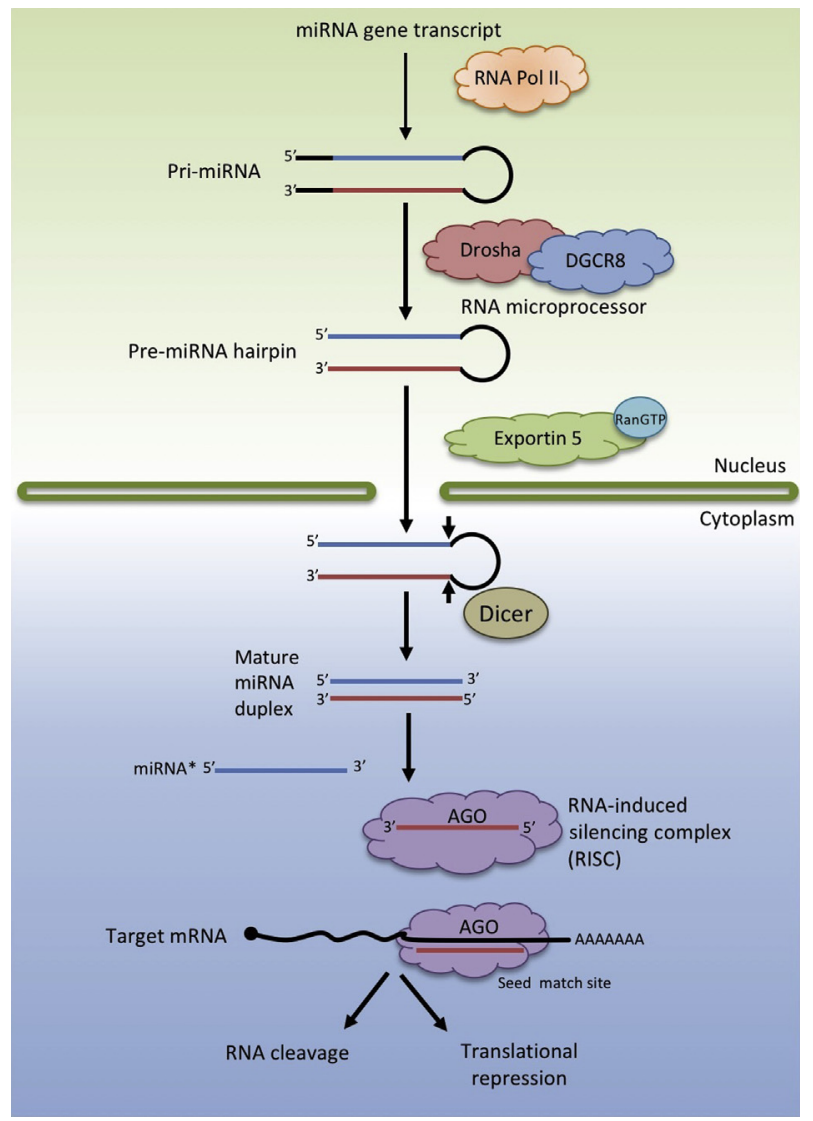

Figure 1 Canonic miRNA biogenesis and post-transcriptional targeting of mRNAs. The miRNA gene is transcribed by RNA polymerase II (RNA Pol II), which then folds back onto itself through complementary binding to form the primary miRNA (pri-miRNA). The ends of the pri-miRNA are then cleaved by the RNA microprocessor complex composed of the RNA endonuclease Drosha and binding partner DiGeorge syndrome chromosome region protein (DGCR)-8 into the pre-miRNA hairpin structure of approximately 60 nucleotides (nt). The pre-miRNA is exported from the nuclease by exportin 5 and guanosine- $5^{\prime}$-triphosphate-binding Ras-related nuclear protein (RAN). In the cytoplasm, the precursor miRNA (pre-miRNA) is cleaved near the loop by the endonuclease Dicer to form the miRNA duplex of approximately 17 to $20 \mathrm{nt}$ in length and consisting of the mature miRNA and a passenger strand, often referred to as the miRNA star $\left(\right.$ miRNA $\left.^{*}\right)$. The mature miRNA is then loaded into the Argonaute protein (AGO) which is part of the RNA-induced silencing complex. The miRNA is then guided to the complementary binding site within the $3^{\prime}$ untranslated region of a target $\mathrm{mRNA}$ where post-transcriptional repression activity in the form of mRNA degradation or translational repression occurs.

(nucleotides 2 to 8 ) to the complementary seed match site of a target mRNA, to direct post-transcriptional repression or mRNA degradation ${ }^{24}$ (Figure 1). According to the most recent update of miRBase software version 22 (http://www.miRBase. org $)^{25}$ there are 1982 human miRNA precursors that produce 2693 mature miRNAs. Importantly, the seed region of any particular miRNA is predicted to target thousands of mRNAs, and each mRNA can have hundreds of miRNA seed match sites within their $3^{\prime}$ untranslated region. Because of this broad regulatory potential, miRNAs are considered the largest class of gene regulators that can fine-tune gene expression ${ }^{26}$ and influence virtually all developmental processes and diseases. ${ }^{24}$ 
In the context of cancer, miRNAs may promote cancer progression through the inhibition of tumor suppressors, or inhibit cancer progression by targeting oncogenes. ${ }^{27}$ Alterations in miRNAs have been described across many types of cancer, including breast cancer. $^{28,29}$ Frequently, global downregulated miRNA expression in tumors relative to normal tissues is observed. In addition, specific miRNA-expression profiles, identified among various cancer types, can both distinguish specific types of tumor from normal tissue and classify tumors according to their common origin. ${ }^{28,30,31}$ miRNA-profiling studies in breast cancer have continually shown that the distinct miRNA-expression patterns present in IDC are also present in DCIS, thus indicating that deregulation of miRNA expression occurs early on in breast cancer development. ${ }^{17,29,32}$ However, the expression profiles and functions of miRNAs differ among the various subtypes of invasive breast cancer (IBC), and also among the subtypes at the DCIS stage. $^{33-35}$

The overall reduction of expressed miRNAs in breast tumor tissues may be attributed to multiple factors, such as changes in the expression levels of the components of the miRNA-processing machinery or growth hormone signaling. For example, the proteins Dicer and Drosha are both downregulated in $\mathrm{IBC}^{36}$ an observation that is also seen in DCIS. The reduction of Dicer expression has been associated with breast cancer progression, particularly in those tumors with reduced hormone receptor expression and of a higher histologic grade, and could independently predict recurrence in the HER2-enriched subtype. ${ }^{37,38}$ Likewise, a gradual loss of Drosha has been observed during the progression of DCIS to metastatic cancer and could serve as an independent predictor of outcome in breast cancer patients. ${ }^{39}$ Approximately $70 \%$ of breast cancers are positive for ER expression, and estrogen signaling plays an important role in breast cancer development and treatment (https://www.cancer.org/research/ cancer-facts-statistics/breast-cancer-facts-figures.html, last accessed June 5, 2018). The role of estrogen and its effects on miRNA expression have been evaluated in various breast and ovarian cancer cells treated with $17 \beta$-estradiol. This treatment resulted in broad repression of the miRNAs required for estrogen-dependent tumor cell growth. ${ }^{40}$ These studies indicate the significance of general miRNAexpression regulation in breast cancer progression.

\section{Role of miRNAs in DCIS Progression}

Although the aberrant expression of miRNAs and their processing machinery in DCIS has been explored, relatively few studies have examined the functional role of miRNAs in the progression of DCIS to IDC. Gene-expression studies in DCIS and IDC have commonly identified genes associated with the pathways involved in cell-cell adhesion, epithelial-tomesenchymal transition (EMT), angiogenesis, and extracellular matrix. However, the most-affected pathways may vary according to intrinsic subtype, with HER2-enriched tumors frequently having disrupted cell-cycle pathways and basal-like tumors enriched for immune-response pathways. ${ }^{12,13,16,23,41}$ Studies examining miRNA function have similarly identified miRNAs that may regulate genes involved in these pathways. The first study to profile the changes in miRNA expression in pre-IBC conducted an integrated mRNA- and miRNAexpression analysis in normal and DCIS tissues. That study identified >100 mRNA:miRNA target pairs involved in several cancer-related pathways, such as cell-cycle regulation, mitogen-activated protein kinase (MAPK) signaling, and p53 interactions. Several of the target pairs were experimentally validated in breast cancer cell lines in vitro. ${ }^{32}$ Loss of miR$125 \mathrm{~b}$ was observed in DCIS tissues compared to normal; overexpression of this putative tumor-suppressor miRNA inhibited the expression of MEMO1, a protein required for HER2-driven cell motility, and the coactivator NRIP1 (alias RIP140), which modulates ER-transcriptional activity. ${ }^{32} \mathrm{miR}$ 182 and -183 were observed to be highly overexpressed in DCIS relative to normal. Inhibition of miR-182 elevated the expression levels of chromobox protein homolog 7 (CBX7), a known oncogene that regulates E-cadherin; docking protein 4 (DOK4), which acts as a scaffold for c-SRC kinase and activates the MAPK pathway; and N-myristoyltransferase (NMT2). The inhibition of miR-183 resulted in elevated expression of the early-response 1 (EGR1), which functions as a transcriptional regulator and potential tumor suppressor. ${ }^{32}$ Importantly, the de-repression of $\mathrm{CBX} 7$, via knockdown of miR-182, resulted in an up-regulation of E-cadherin, a key protein whose loss of function is known to contribute to breast cancer progression. Additional studies have been conducted to validate some of the target pairs identified in this study across various cancer types, indicating that these interactions are highly relevant to neoplastic progression. ${ }^{42-44}$

Other studies have examined the expression and function of miRNAs in the context of hormonal receptor signaling, transforming growth factor (TGF)- $\beta$ signaling, EMT, and cancer stem cells in DCIS and IDC. For example, the let-7 family of miRNAs were found to be down-regulated in formalin-fixed, paraffin-embedded DCIS and IDC tissues relative to benign and to be inversely correlated with the expression of ER- $\alpha$. In vitro experiments validated the effect of let-7 overexpression on reducing the signaling activity and expression of ER- $\alpha{ }^{45}$ TGF- $\beta$ signaling plays a complex role in breast cancer progression. TGF- $\beta$ acts as a tumor suppressor by inhibiting epithelial cell-cycle progression and promoting apoptosis during the early stages of carcinogenesis, while promoting metastasis in later stages of cancer progression. ${ }^{46}$ Chen et $\mathrm{al}^{47}$ profiled the miRNA expression in formalinfixed, paraffin- embedded tissues from normal, atypical ductal hyperplasia, DCIS, and IDC samples. In that study, the expression levels of miR-21, -200b/c, -183, and -141 were consistently increased in atypical ductal hyperplasia, DCIS, and IDC compared to normal, whereas the expression of miR557 was consistently decreased in DCIS. miRNA target gene prediction and pathway analysis indicated that the oncomiR miR-21 may promote breast cancer progression by regulating 
TGF- $\beta$ signaling. miR-21 is known to regulate the TGF- $\beta$ pathway by repressing the activity of inhibitors of TGF- $\beta$ signaling, such as SMAD7. Meanwhile, active TGF- $\beta$ signaling can increase levels of mature miR-21 in a feedforward loop. Knockdown of miR-21 in breast cancer cell lines can restore the expression of MSH2 and SMAD7, which are both involved in the TGF- $\beta$ pathway, indicating that miR21 may play an important role in selectively utilizing the TGF$\beta$ pathway during breast cancer initiation and progression. ${ }^{48}$ Another study identified a crucial role for TGF- $\beta$ signaling in the tumor microenvironment. In the mammary gland, the luminal epithelial cells, which are the most common cell type of neoplastic origin in the breast, are surrounded by a layer of myoepithelial cells that normally function to maintain luminal cell polarity and the structural integrity of the mammary ductal system. However, the myoepithelial cell layer is progressively lost during tumor development. ${ }^{49}$ In this study, the relationship of tumor-associated myoepithelial cells with DCIS cells was examined. Under co-culture conditions, the DCIS cells were found to stimulate the myoepithelial cells to secrete TGF- $\beta_{1}$, which in return contributed to the activation of the TGF- $\beta$ / mothers against decapentaplegic homolog pathway and the induction of oncogenic miR-10b-5p, increased EMT, enhanced basal-like phenotypes, induction of stemness, and invasiveness of the DCIS cells. The induction of miR-10b-5p resulted in the down-regulation of its tumor-suppressor target RB1-inducible coiled-coil 1 (RB1CC1), contributing to the invasive progression of DCIS cells. ${ }^{50}$

EMT is a crucial process for promoting cancer invasion, by reducing intercellular junctions and loss of cell polarity, while enhancing the migratory behavior, resistance to apoptosis, and production of extracellular-matrix components. The miR-200 family (miR-200a-c, -141, and -429) has repeatedly been shown to play an important role in EMT through the regulation of genes involved in this process. ${ }^{51,52} \mathrm{Up}$ regulation of the miR-200 family is consistently reported in the early stages of breast cancer development; however, expression is either unchanged or reportedly lost in the transition to invasive cancers. ${ }^{17,53}$ For example, miR-200a expression was progressively lost with cancer progression in formalin-fixed, paraffin- embedded tissues from normal, DCIS, to IDC, and in metastatic lymph nodes. miR-200a expression was detected in $95 \%$ of normal and $80 \%$ of DCIS samples, whereas only $42 \%$ and $17 \%$ of IDC and metastatic lymph nodes, respectively, were positive for miR200a expression. In addition, the loss of miR-200a expression was correlated with high histologic grade and perinodal tumor extension. ${ }^{53}$ These results suggest that the loss of EMTrelated miRNA, such as miR-200a, may play an important role in DCIS progression to invasive disease.

Cancer stem cells are a specific group of immortal cells, among the other cancerous cells within the tumor, that can self-renew and sustain tumor growth. ${ }^{54}$ Studies have shown that DCIS may contain a population of cancer stem cells. ${ }^{55} \mathrm{~A}$ miRNA-profiling study in DCIS and matched normal controls showed that 68 miRNAs were dysregulated in DCIS relative to normal. ${ }^{56}$ miR-140 was found to be among the most consistently down-regulated miRNAs. With the separation of CD44-high/CD24-low DCIS cell subpopulations, which are associated with stemness, miR-140 was significantly down-regulated in cancer stem-like cells compared to normal stem cells. They also identified the stem-cell factors sex-determining region (SR) Y box 9 (SOX9) and aldehyde dehydrogenase 1 (ALDH1) as direct targets of miR-140. Increased expression of miR-140 decreased the levels of both SOX9 and ALDH1, and resulted in reduced tumor growth in vivo, demonstrating that miR-140 contributes to the growth and survival of cancer stem cells in DCIS. ${ }^{56}$ However, whether cancer stem cells may influence the invasive potential of DCIS remains unclear.

More recent differential miRNA-profiling studies have sought to determine the role of miRNAs in DCIS progression. In a study by Li et al,${ }^{57}$ miRNA microarray and real-time PCR were utilized to profile miRNAs in 21 DCIS samples and matching normal tissues. They identified miR-10b, $-125 \mathrm{~b}$, $-132,-145,-154-3 p,-382-5 p$, and $-409-3 p$ as significantly down-regulated in DCIS relative to normal. Re-expression of miR-132, a potential tumor-suppressor miRNA, inhibited the proliferation and colony-forming ability of breast cancer cells, indicating a potential role for this miRNA in the early stages of breast cancer development.

Intravasation of cancer cells into the small intratumor vessels, known as lymphovascular invasion, is regularly evaluated in pathology reports and may indicate an increased risk for cancer spread. ${ }^{58}$ Altered miRNA expression in breast cancer cells microdissected from the lymphovascular space, compared to matched DCIS and IBC samples, was recently examined. In that study, the authors identified high expression levels of miR-150, -126, and -155 in IBC and lymphovascular invasion compared to DCIS samples and validated their expression in breast cancer cell lines in vitro. Several target genes of these miRNAs with various roles in cancer progression, including RHOA, a GTPase associated with proliferation and metastasis; PEG10, an inhibitor of TGF- $\beta$ signaling; and the proto-oncogene MYB, were highly expressed in DCIS relative to IBC and lymphovascular invasion, suggesting a role for these miRNAs in the progression of breast cancer. ${ }^{59}$

The changes in miRNA expression during breast cancer progression have also been examined in an animal model. ${ }^{60}$ In that study, both mRNA and miRNA expression were measured at four key time points of breast cancer progression using the polyoma middle $\mathrm{T}$ antigen mouse model of luminal B breast cancer. During the entire course of disease progression, 151 miRNAs were differentially regulated, with the number of differentially overexpressed miRNAs increasing along four set time points corresponding to the stages of human breast cancer progression (hyperplasia, adenoma/ mammary intraepithelial neoplasia, early carcinoma, and late carcinoma with metastasis). By combining both expression data sets and miRNA target prediction, $>10,000$ potential miRNA:mRNA interactions were identified. Target gene 


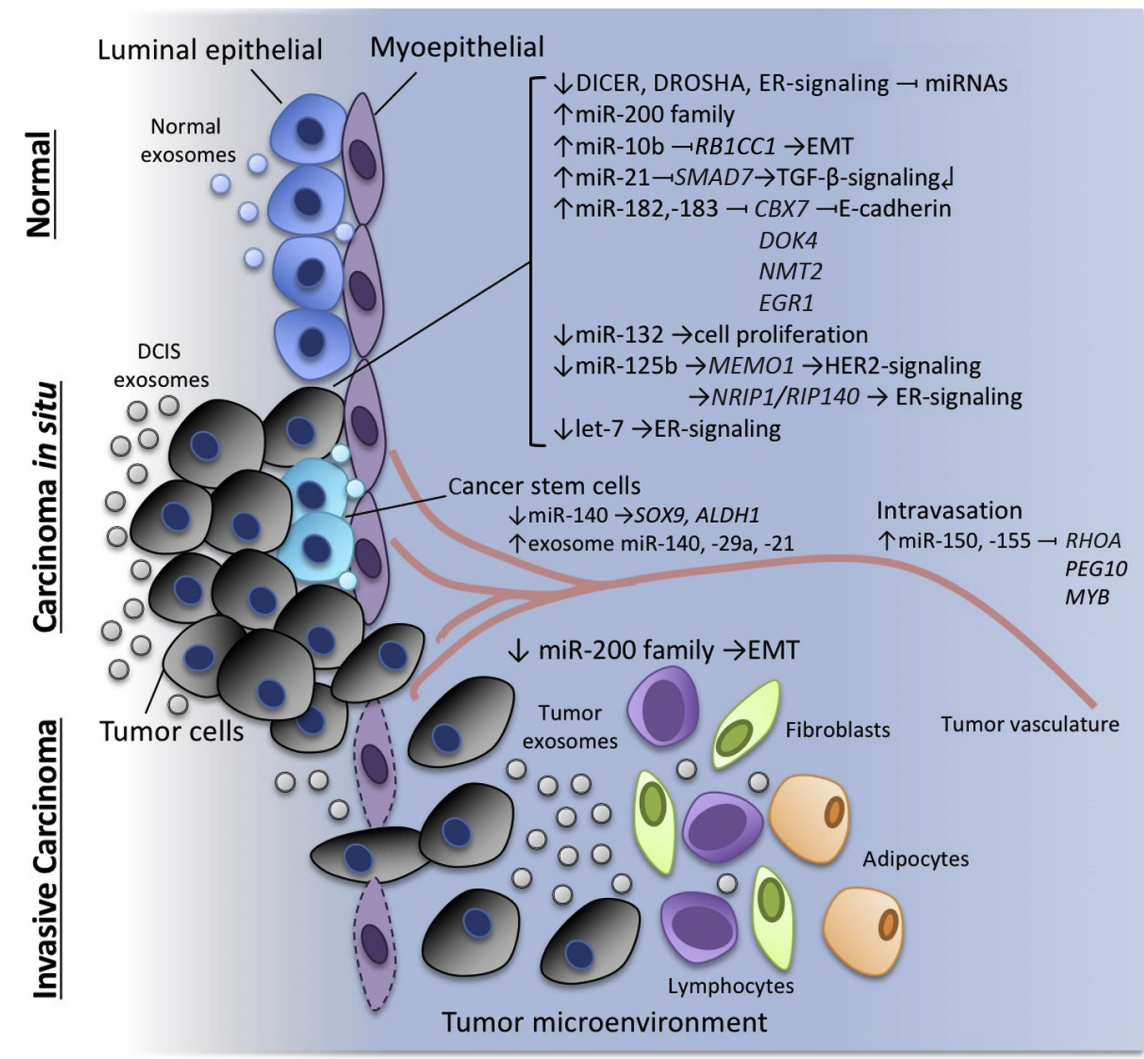

Figure 2 A hypothetical model of the role of miRNAs in the progression of ductal carcinoma in situ (DCIS). The normal breast epithelium is composed of luminal epithelial and myoepithelial cells. Breast cancer initiation and development are characterized by common mutational events, uncontrolled cell proliferation, and reduced apoptosis in the luminal epithelial cell layer. miRNA expression may be altered due to loss of Dicer and Drosha expression and estrogen receptor signaling. Expression of oncogenic miRNAs is activated and expression of tumor suppressor miRNAs is deactivated, allowing continued growth and proliferation through enhanced transforming growth factor (TGF)- $\beta$, estrogen receptor (ER), and human epidermal growth factor receptor (HER)-2 signaling, and loss of E-cadherin that leads to reduced cell-cell and cell-matrix adhesions. Tumor vasculature expands due to low oxygen levels and proangiogenic stimuli in the tumor microenvironment. Loss of miR-140 expression in cancer stem cells leads to sustained tumor growth and survival. Myoepithelial cell layer undergoes changes in gene expression, leading to a compromised cell layer that allows tumor cells that are undergoing epithelial-to-mesenchymal transition (EMT) to invade into the surrounding stroma. Further spreading of cancer cells into the lymphovascular space involves the intravasation of cancer cells into the small vessels within the tumor and may be an early indicator of metastasis. It has recently become clearer that there is a mutual interaction between tumor cells and stromal cells via exosome miRNA signaling. In this model, the tumor-derived exosomes carrying miRNAs can communicate with stromal cells such as fibroblasts, lymphocytes, and adipocytes, which in turn support the growth of the tumor.

annotation and pathway analysis found an enrichment for targets involved in cell and focal adhesion, cell migration, angiogenesis, and tight junctions, with the number of targets among these groups increasing with cancer progression. Notably, miRNAs with target genes related to angiogenesis were more active during the early transition of dysplasia to adenoma. Meanwhile, miRNAs with target genes related to proliferation, cell adhesion, differentiation, lipid metabolism, and transmembrane transports were more active in the later stages of early carcinoma to metastasis, and miRNAs with target genes related to Tgf- $\beta$ signaling showed decreased activity at this time point. ${ }^{60}$

\section{Role of Extracellular miRNAs in DCIS}

Due to the high similarity of expression profiles between DCIS and IBC and the lack of a reliable indicator of the invasive process, it has been suggested that the extrinsic factors present in the breast tumor microenvironment may play an important role in the progression of DCIS to IBC. The breast cancer microenvironment is composed of many different cell types, including myoepithelial cells, stromal fibroblasts, adipocytes, vascular endothelial cells, and immune cells, as well as the extracellular matrix. The crosstalk between cancer cells and stromal cells is considered an important factor in creating a permissive environment for invasive progression. ${ }^{61}$ In addition to the role of miRNAs in influencing cancer-associated proliferation, angiogenesis, and metastasis, as discussed in Role of miRNAs in DCIS Progression, the role of the immune microenvironment has recently begun to be appreciated. Tumor-infiltrating lymphocytes present in the stroma have been associated with certain prognostic features, such as larger tumor size, high nuclear grade, comedo type with necrosis, and ER negativity, and are mainly present in HER2-enriched and triple-negative DCIS. However, tumor-infiltrating lymphocytes seem to have a dichotomous role in DCIS progression, with some studies suggesting that they have an inhibitory effect on invasion in HER2-enriched DCIS, and a proinvasive effect in triplenegative DCIS. ${ }^{62}$ Several studies have shown that miRNAs control critical functions of tumor-associated immune-system cells and can modulate the cancer-related immune response and affect IBC progression. However, a role for miRNA regulation of tumor-infiltrating lymphocytes at the DCIS stage is yet to be explored. 
Table 1 Summary and Functional Role of miRNAs in DCIS Progression

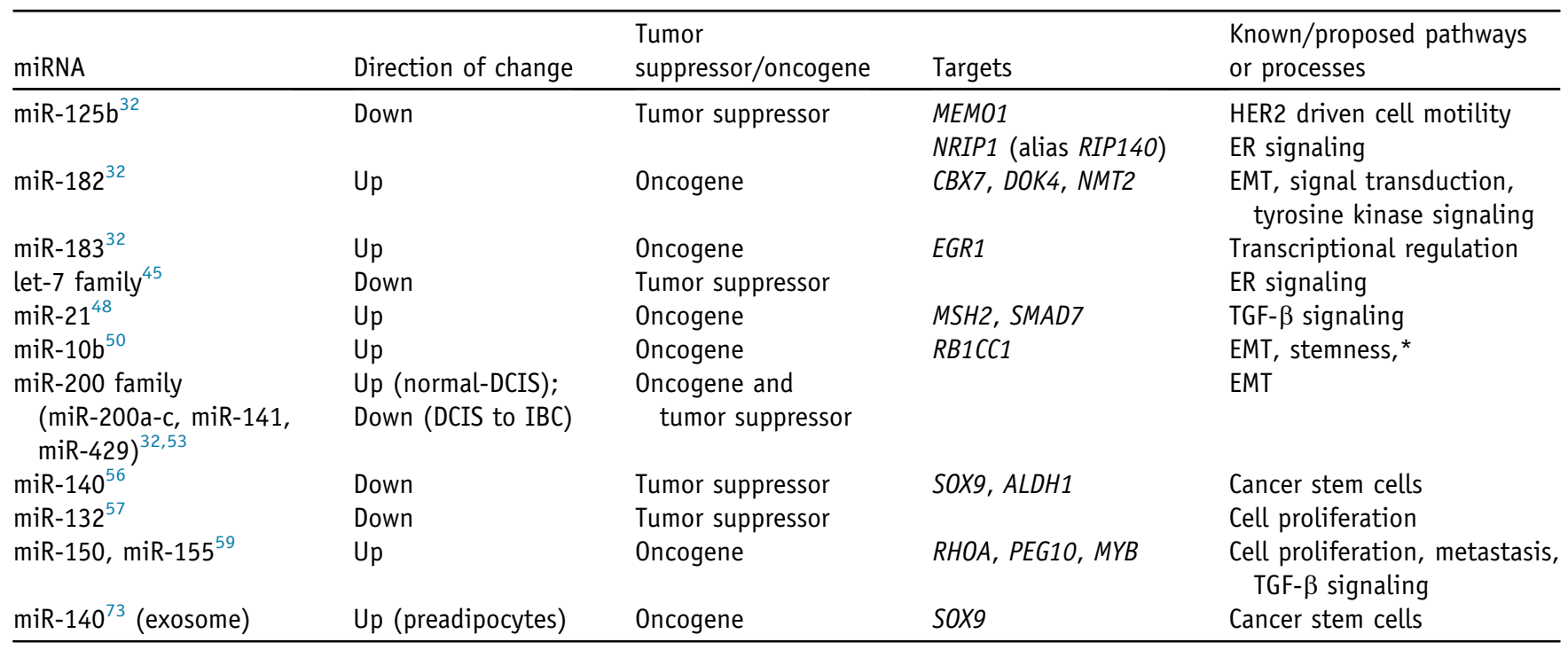

*Stemness is defined as the ability to self-renew and differentiate.

DCIS, ductal carcinoma in situ; EMT, epithelial to mesenchymal transition; ER, estrogen receptor; HER2, human epidermal growth factor receptor 2, IBC, invasive breast cancer; TGF, transforming growth factor.

miRNAs have recently emerged as important regulatory mediators of cellular crosstalk in the tumor microenvironment. Endogenously produced miRNAs can be secreted from cancer cells to the tumor microenvironment via nanometer-sized extracellular vesicles called exosomes $(50$ to $100 \mathrm{~nm}){ }^{63}$ Under hypoxic conditions, breast cancer cells can secrete greater numbers of exosomes compared to normal cells. ${ }^{64}$ Exosomes have been shown to transport oncogenic factors, including miRNAs, that may remodel the tumor microenvironment, thereby contributing to breast cancer progression. ${ }^{65-69}$ Breast cancer cells selectively secrete certain miRNAs in exosomes ${ }^{70}$ that are detectable in plasma samples derived from xenograft mouse models and breast cancer patients and may indicate the presence of breast cancer. ${ }^{71}$ Very little research has been conducted to explore the influence of exosome miRNAs in the DCIS microenvironment and how they may regulate breast cancer progression. However, Zhou and colleagues ${ }^{72,73}$ have reported on the role of exosome miRNA trafficking in DCIS. Their research has shown that exosomes from DCIS stemlike cells contain miR-140, -29a, and -21 , and that these miRNAs can be transferred to other cell types. ${ }^{72}$ Preadipocytes were also shown to secrete high levels of miR-140 that affected SOX9 signaling in DCIS cells and promoted tumorigenesis. ${ }^{73}$ A continued effort in this area of research would greatly contribute to our understanding of the role of the tumor microenvironment in the progression of DCIS to invasive disease.

In summary, miRNAs play a role in influencing both the intracellular and intercellular signaling pathways that may contribute to invasive progression. A hypothetical model of the role of miRNAs in breast cancer progression is presented in Figure 2, and a summary of the miRNAs discussed in this review, along with their described target genes and their influence on known or potential pathways, is included in Table 1.

\section{Therapeutic Targeting of miRNA}

Due to the function of miRNAs in maintaining cell homeostasis and their ability to specifically target and silence gene expression, miRNAs and siRNAs are considered an important area of therapeutic drug research and development. The first miRNA therapeutic, called miravirsen (Santaris Pharma, Copenhagen, Denmark), is an inhibitor of miR-122. Miravirsen is currently in phase IIA clinical trials for the treatment of hepatitis $\mathrm{C}$ virus infection. ${ }^{74}$ Many RNA therapeutics are in the various stages of preclinical and clinical development for cardiovascular disease, other cancer types, and viral infections. ${ }^{75}$ Significant interest is evident in the development of miRNA and siRNA therapeutics for breast cancer. For example, the highest number of siRNA-related cancer therapeutic patents granted in the United States were for breast cancer applications. ${ }^{76}$ However, this high volume of patents has not yet resulted in any clinical trials of RNA therapeutics for breast cancer.

The primary challenges facing the development of miRNA-based therapeutics for breast cancer include:

i) The lack of conclusive evidence supporting the clinical utility of any specific miRNA for the treatment of breast cancer, especially in preinvasive DCIS. The inconsistency among various studies can primarily be attributed to differences in the type, stage, and number of clinical specimens utilized, as well as the methods of data generation and chosen platform for molecular analysis. 
ii) A robust understanding not only of the molecular mechanisms involved in the miRNA regulation of breast cancer development and progression, but also of the role of a particular miRNA in normal tissue homeostasis. This information is crucial to specifically target cancer cells, while reducing the risk for adverse off-target effects.

iii) The complex inter- and intratumor heterogeneity of breast cancer. It has been firmly established that the clinical response to current therapies for breast cancer patients is dependent on the breast cancer subtype, and it is therefore likely that the response to miRNA therapies would also be subtype dependent. In addition, the field of RNAtherapeutic development has been challenged by effective delivery of a particular miRNA or siRNA to its target tissue. Several issues with the pharmacologic properties of RNAbased therapeutics have been observed, including off-target effects, low stability in the serum, and innate immune responses. ${ }^{77,78}$ With the latter resulting in the cancellation of a phase I clinical trial of MRX-34 (Mirna Therapeutics, Inc., Austin, TX), which delivers an miR-34 miRNA mimic for the treatment of primary liver cancer, advanced solid tumors, and hematologic malignancies. ${ }^{79}$ New areas of RNAtherapeutic delivery that may provide better bioavailability, such as cationic liposomes ${ }^{78}$ and engineered exosomes, ${ }^{80}$ are being explored due to their ability to encapsulate and deliver small, negatively charged RNAs.

The idea of using RNA therapeutics as a preventive agent to block DCIS from transitioning to IDC is an attractive yet unexplored area of research. However, a thorough understanding of the miRNA-expression patterns and function specifically associated with the cellular processes involved in the progression to invasive disease, and a robust preclinical analysis, are required for miRNA-based therapeutics to become a reality.

\section{Summary and Future Perspectives}

miRNA expression is dysregulated very early in breast cancer development, and these changes have important roles in modulating gene expression and pathways crucial for invasive progression. Endogenous miRNAs in DCIS cells influence gene-expression programs that may promote tumorigenic behavior, and extracellular miRNAs can influence the behavior of cells in the tumor microenvironment. Although progress has been made, taken together, the expression and functional role of miRNAs in DCIS progression are both complex and poorly understood. More scientific effort is obviously needed in furthering the understanding of the functional role of miRNAs in the progression of DCIS. Better models able to integrate both the microenvironment and tumor cell factors will greatly advance the understanding of the miRNA biology of breast cancer progression and enhance the ability to better predict invasive progression and therapeutically target DCIS before its advancement to invasive disease.

\section{Acknowledgments}

B.N.H. conceived of, drafted, and revised the manuscript; W.-Q.D. drafted and revised the manuscript; both authors read and approved the final manuscript.

\section{References}

1. Lopez-Garcia MA, Geyer FC, Lacroix-Triki M, Marchio C, ReisFilho JS: Breast cancer precursors revisited: molecular features and progression pathways. Histopathology 2010, 57:171-192

2. Allegra CJ, Aberle DR, Ganschow P, Hahn SM, Lee CN, MillonUnderwood S, Pike MC, Reed SD, Saftlas AF, Scarvalone SA, Schwartz AM, Slomski C, Yothers G, Zon R: NIH state-of-thescience conference statement: diagnosis and management of ductal carcinoma in situ (DCIS). NIH Consens State Sci Statements 2009 , 26:1-27

3. Perou CM, Sorlie T, Eisen MB, van de Rijn M, Jeffrey SS, Rees CA, Pollack JR, Ross DT, Johnsen H, Akslen LA, Fluge O, Pergamenschikov A, Williams C, Zhu SX, Lonning PE, BorresenDale AL, Brown PO, Botstein D: Molecular portraits of human breast tumours. Nature 2000, 406:747-752

4. Sorlie T, Tibshirani R, Parker J, Hastie T, Marron JS, Nobel A, Deng S, Johnsen H, Pesich R, Geisler S, Demeter J, Perou CM, Lonning PE, Brown PO, Borresen-Dale AL, Botstein D: Repeated observation of breast tumor subtypes in independent gene expression data sets. Proc Natl Acad Sci U S A 2003, 100:8418-8423

5. Tamimi RM, Colditz GA, Hazra A, Baer HJ, Hankinson SE, Rosner B, Marotti J, Connolly JL, Schnitt SJ, Collins LC: Traditional breast cancer risk factors in relation to molecular subtypes of breast cancer. Breast Cancer Res Treat 2012, 131:159-167

6. Zhou W, Jirstrom K, Amini RM, Fjallskog ML, Sollie T, Lindman H, Sorlie T, Blomqvist C, Warnberg F: Molecular subtypes in ductal carcinoma in situ of the breast and their relation to prognosis: a population-based cohort study. BMC Cancer 2013, 13:512

7. Bartlett JM, Nofech-Moses S, Rakovitch E: Ductal carcinoma in situ of the breast: can biomarkers improve current management? Clin Chem 2014, 60:60-67

8. Aubele M, Mattis A, Zitzelsberger H, Walch A, Kremer M, Welzl G, Hofler H, Werner M: Extensive ductal carcinoma In situ with small foci of invasive ductal carcinoma: evidence of genetic resemblance by CGH. Int J Cancer 2000, 85:82-86

9. Foschini MP, Morandi L, Leonardi E, Flamminio F, Ishikawa Y, Masetti R, Eusebi V: Genetic clonal mapping of in situ and invasive ductal carcinoma indicates the field cancerization phenomenon in the breast. Hum Pathol 2013, 44:1310-1319

10. Kim SY, Jung SH, Kim MS, Baek IP, Lee SH, Kim TM, Chung YJ, Lee SH: Genomic differences between pure ductal carcinoma in situ and synchronous ductal carcinoma in situ with invasive breast cancer. Oncotarget 2015, 6:7597-7607

11. Kroigard AB, Larsen MJ, Laenkholm AV, Knoop AS, Jensen JD, Bak M, Mollenhauer J, Kruse TA, Thomassen M: Clonal expansion and linear genome evolution through breast cancer progression from pre-invasive stages to asynchronous metastasis. Oncotarget 2015, 6 : 5634-5649

12. Lee S, Stewart S, Nagtegaal I, Luo J, Wu Y, Colditz G, Medina D, Allred DC: Differentially expressed genes regulating the progression of ductal carcinoma in situ to invasive breast cancer. Cancer Res 2012, 72:4574-4586

13. Muggerud AA, Hallett M, Johnsen H, Kleivi K, Zhou W, Tahmasebpoor S, Amini RM, Botling J, Borresen-Dale AL, Sorlie T, Warnberg F: Molecular diversity in ductal carcinoma in situ (DCIS) and early invasive breast cancer. Mol Oncol 2010, 4:357-368

14. Ma XJ, Salunga R, Tuggle JT, Gaudet J, Enright E, McQuary P, Payette T, Pistone M, Stecker K, Zhang BM, Zhou YX, Varnholt H, 
Smith B, Gadd M, Chatfield E, Kessler J, Baer TM, Erlander MG, Sgroi DC: Gene expression profiles of human breast cancer progression. Proc Natl Acad Sci U S A 2003, 100:5974-5979

15. Porter D, Lahti-Domenici J, Keshaviah A, Bae YK, Argani P, Marks J, Richardson A, Cooper A, Strausberg R, Riggins GJ, Schnitt S, Gabrielson E, Gelman R, Polyak K: Molecular markers in ductal carcinoma in situ of the breast. Mol Cancer Res 2003, 1:362-375

16. Abba MC, Gong T, Lu Y, Lee J, Zhong Y, Lacunza E, Butti M, Takata Y, Gaddis S, Shen J, Estecio MR, Sahin AA, Aldaz CM: A molecular portrait of high-grade ductal carcinoma in situ. Cancer Res 2015, 75:3980-3990

17. Hannafon BN, Ding WQ: miRNAs as biomarkers for predicting the progression of ductal carcinoma in situ. Am J Pathol 2018, 188: $542-549$

18. Casasent AK, Edgerton M, Navin NE: Genome evolution in ductal carcinoma in situ: invasion of the clones. J Pathol 2017, 241: $208-218$

19. Pang JB, Savas P, Fellowes AP, Mir Arnau G, Kader T, Vedururu R, Hewitt C, Takano EA, Byrne DJ, Choong DY, Millar EK, Lee CS, O'Toole SA, Lakhani SR, Cummings MC, Mann GB, Campbell IG, Dobrovic A, Loi S, Gorringe KL, Fox SB: Breast ductal carcinoma in situ carry mutational driver events representative of invasive breast cancer. Mod Pathol 2017, 30:952-963

20. Cancer Genome Atlas Network: Comprehensive molecular portraits of human breast tumours. Nature 2012, 490:61-70

21. Hernandez L, Wilkerson PM, Lambros MB, Campion-Flora A, Rodrigues DN, Gauthier A, Cabral C, Pawar V, Mackay A, A'Hern R, Marchio C, Palacios J, Natrajan R, Weigelt B, Reis-Filho JS: Genomic and mutational profiling of ductal carcinomas in situ and matched adjacent invasive breast cancers reveals intra-tumour genetic heterogeneity and clonal selection. J Pathol 2012, 227:42-52

22. Banerji S, Cibulskis K, Rangel-Escareno C, Brown KK, Carter SL, Frederick AM, et al: Sequence analysis of mutations and translocations across breast cancer subtypes. Nature 2012, 486:405-409

23. Lesurf R, Aure MR, Mork HH, Vitelli V, Oslo Breast Cancer Research C, Lundgren S, Borresen-Dale AL, Kristensen V, Warnberg F, Hallett M, Sorlie T: Molecular features of subtypespecific progression from ductal carcinoma in situ to invasive breast cancer. Cell Rep 2016, 16:1166-1179

24. Bartel DP: Metazoan MicroRNAs. Cell 2018, 173:20-51

25. Kozomara A, Griffiths-Jones S: miRBase: annotating high confidence microRNAs using deep sequencing data. Nucleic Acids Res 2014, 42: D68-D73

26. Lim LP, Lau NC, Garrett-Engele P, Grimson A, Schelter JM, Castle J, Bartel DP, Linsley PS, Johnson JM: Microarray analysis shows that some microRNAs downregulate large numbers of target mRNAs. Nature 2005, 433:769-773

27. Melo SA, Esteller M: Dysregulation of microRNAs in cancer: playing with fire. FEBS Lett 2011, 585:2087-2099

28. Lu J, Getz G, Miska EA, Alvarez-Saavedra E, Lamb J, Peck D, Sweet-Cordero A, Ebert BL, Mak RH, Ferrando AA, Downing JR, Jacks T, Horvitz HR, Golub TR: MicroRNA expression profiles classify human cancers. Nature 2005, 435:834-838

29. Iorio MV, Ferracin M, Liu CG, Veronese A, Spizzo R, Sabbioni S, Magri E, Pedriali M, Fabbri M, Campiglio M, Menard S, Palazzo JP, Rosenberg A, Musiani P, Volinia S, Nenci I, Calin GA, Querzoli P, Negrini M, Croce CM: MicroRNA gene expression deregulation in human breast cancer. Cancer Res 2005, 65:7065-7070

30. Kumar MS, Lu J, Mercer KL, Golub TR, Jacks T: Impaired microRNA processing enhances cellular transformation and tumorigenesis. Nat Genet 2007, 39:673-677

31. Ozen M, Creighton CJ, Ozdemir M, Ittmann M: Widespread deregulation of microRNA expression in human prostate cancer. Oncogene 2008, 27:1788-1793

32. Hannafon BN, Sebastiani P, de las Morenas A, Lu J, Rosenberg CL: Expression of microRNA and their gene targets are dysregulated in preinvasive breast cancer. Breast Cancer Res 2011, 13:R24
33. Farazi TA, Horlings HM, Ten Hoeve JJ, Mihailovic A, Halfwerk H, Morozov P, Brown M, Hafner M, Reyal F, van Kouwenhove M, Kreike B, Sie D, Hovestadt V, Wessels LF, van de Vijver MJ, Tuschl T: MicroRNA sequence and expression analysis in breast tumors by deep sequencing. Cancer Res 2011, 71:4443-4453

34. Volinia S, Galasso M, Sana ME, Wise TF, Palatini J, Huebner K, Croce CM: Breast cancer signatures for invasiveness and prognosis defined by deep sequencing of microRNA. Proc Natl Acad Sci U S A 2012, 109:3024-3029

35. Haakensen VD, Nygaard V, Greger L, Aure MR, Fromm B, Bukholm IR, Luders T, Chin SF, Git A, Caldas C, Kristensen VN, Brazma A, Borresen-Dale AL, Hovig E, Helland A: Subtype-specific micro-RNA expression signatures in breast cancer progression. Int $\mathrm{J}$ Cancer 2016, 139:1117-1128

36. Dedes KJ, Natrajan R, Lambros MB, Geyer FC, Lopez-Garcia MA, Savage K, Jones RL, Reis-Filho JS: Down-regulation of the miRNA master regulators Drosha and Dicer is associated with specific subgroups of breast cancer. Eur J Cancer 2011, 47:138-150

37. Khoshnaw SM, Rakha EA, Abdel-Fatah TM, Nolan CC, Hodi Z, Macmillan DR, Ellis IO, Green AR: Loss of Dicer expression is associated with breast cancer progression and recurrence. Breast Cancer Res Treat 2012, 135:403-413

38. Blenkiron C, Goldstein LD, Thorne NP, Spiteri I, Chin SF, Dunning MJ, Barbosa-Morais NL, Teschendorff AE, Green AR, Ellis IO, Tavare S, Caldas C, Miska EA: MicroRNA expression profiling of human breast cancer identifies new markers of tumor subtype. Genome Biol 2007, 8:R214

39. Khoshnaw SM, Rakha EA, Abdel-Fatah T, Nolan CC, Hodi Z, Macmillan RD, Ellis IO, Green AR: The microRNA maturation regulator Drosha is an independent predictor of outcome in breast cancer patients. Breast Cancer Res Treat 2013, 137:139-153

40. Maillot G, Lacroix-Triki M, Pierredon S, Gratadou L, Schmidt S, Benes V, Roche H, Dalenc F, Auboeuf D, Millevoi S, Vagner S: Widespread estrogen-dependent repression of microRNAs involved in breast tumor cell growth. Cancer Res 2009, 69:8332-8340

41. Vargas AC, McCart Reed AE, Waddell N, Lane A, Reid LE, Smart CE, Cocciardi S, da Silva L, Song S, Chenevix-Trench G, Simpson PT, Lakhani SR: Gene expression profiling of tumour epithelial and stromal compartments during breast cancer progression. Breast Cancer Res Treat 2012, 135:153-165

42. Ibrahim SA, Yip GW, Stock C, Pan JW, Neubauer C, Poeter M, Pupjalis D, Koo CY, Kelsch R, Schule R, Rescher U, Kiesel L, Gotte M: Targeting of syndecan-1 by microRNA miR-10b promotes breast cancer cell motility and invasiveness via a Rho-GTPase- and Ecadherin-dependent mechanism. Int J Cancer 2012, 131:E884-E896

43. Tsai DY, Hung KH, Lin IY, Su ST, Wu SY, Chung CH, Wang TC, Li WH, Shih AC, Lin KI: Uncovering microRNA regulatory hubs that modulate plasma cell differentiation. Sci Rep 2015, 5:17957

44. Zhang ZF, Wang YJ, Fan SH, Du SX, Li XD, Wu DM, Lu J, Zheng YL: MicroRNA-182 downregulates Wnt/beta-catenin signaling, inhibits proliferation, and promotes apoptosis in human osteosarcoma cells by targeting HOXA9. Oncotarget 2017, 8:101345-101361

45. Zhao Y, Deng C, Wang J, Xiao J, Gatalica Z, Recker RR, Xiao GG: Let-7 family miRNAs regulate estrogen receptor alpha signaling in estrogen receptor positive breast cancer. Breast Cancer Res Treat 2011, 127:69-80

46. Tang B, Vu M, Booker T, Santner SJ, Miller FR, Anver MR, Wakefield LM: TGF-beta switches from tumor suppressor to prometastatic factor in a model of breast cancer progression. J Clin Invest 2003, 112:1116-1124

47. Chen L, Li Y, Fu Y, Peng J, Mo MH, Stamatakos M, Teal CB, Brem RF, Stojadinovic A, Grinkemeyer M, McCaffrey TA, Man YG, Fu SW: Role of deregulated microRNAs in breast cancer progression using FFPE tissue. PLoS One 2013, 8:e54213

48. Davis BN, Hilyard AC, Nguyen PH, Lagna G, Hata A: Smad proteins bind a conserved RNA sequence to promote microRNA maturation by Drosha. Mol Cell 2010, 39:373-384 
49. Man YG, Sang QX: The significance of focal myoepithelial cell layer disruptions in human breast tumor invasion: a paradigm shift from the "protease-centered" hypothesis. Exp Cell Res 2004, 301:103-118

50. Lo PK, Zhang Y, Yao Y, Wolfson B, Yu J, Han SY, Duru N, Zhou Q: Tumor-associated myoepithelial cells promote the invasive progression of ductal carcinoma in situ through activation of TGFbeta signaling. J Biol Chem 2017, 292:11466-11484

51. Korpal M, Lee ES, Hu G, Kang Y: The miR-200 family inhibits epithelial-mesenchymal transition and cancer cell migration by direct targeting of E-cadherin transcriptional repressors ZEB1 and ZEB2. J Biol Chem 2008, 283:14910-14914

52. Gregory PA, Bracken CP, Smith E, Bert AG, Wright JA, Roslan S, Morris M, Wyatt L, Farshid G, Lim YY, Lindeman GJ, Shannon MF, Drew PA, Khew-Goodall Y, Goodall GJ: An autocrine TGFbeta/ZEB/miR-200 signaling network regulates establishment and maintenance of epithelial-mesenchymal transition. Mol Biol Cell 2011, 22:1686-1698

53. Jang K, Ahn H, Sim J, Han H, Abdul R, Paik SS, Chung MS, Jang SJ: Loss of microRNA-200a expression correlates with tumor progression in breast cancer. Transl Res 2014, 163:242-251

54. Batlle E, Clevers H: Cancer stem cells revisited. Nat Med 2017, 23 : $1124-1134$

55. Espina V, Mariani BD, Gallagher RI, Tran K, Banks S, Wiedemann J, Huryk H, Mueller C, Adamo L, Deng J, Petricoin EF, Pastore L, Zaman S, Menezes G, Mize J, Johal J, Edmiston K, Liotta LA: Malignant precursor cells pre-exist in human breast DCIS and require autophagy for survival. PLoS One 2010, 5:e10240

56. Li Q, Yao Y, Eades G, Liu Z, Zhang Y, Zhou Q: Downregulation of miR-140 promotes cancer stem cell formation in basal-like early stage breast cancer. Oncogene 2014, 33:2589-2600

57. Li S, Meng H, Zhou F, Zhai L, Zhang L, Gu F, Fan Y, Lang R, Fu L, Gu L, Qi L: MicroRNA-132 is frequently down-regulated in ductal carcinoma in situ (DCIS) of breast and acts as a tumor suppressor by inhibiting cell proliferation. Pathol Res Pract 2013, 209:179-183

58. Rakha EA, Martin S, Lee AH, Morgan D, Pharoah PD, Hodi Z, MacMillan D, Ellis IO: The prognostic significance of lymphovascular invasion in invasive breast carcinoma. Cancer 2012, 118: $3670-3680$

59. Soon PS, Provan PJ, Kim E, Pathmanathan N, Graham D, Clarke CL, Balleine RL: Profiling differential microRNA expression between in situ, infiltrative and lympho-vascular space invasive breast cancer: a pilot study. Clin Exp Metastasis 2018, 35:3-13

60. Nogales-Cadenas R, Cai Y, Lin JR, Zhang Q, Zhang W, Montagna C, Zhang ZD: MicroRNA expression and gene regulation drive breast cancer progression and metastasis in PyMT mice. Breast Cancer Res 2016, 18:75

61. Hu M, Polyak K: Molecular characterisation of the tumour microenvironment in breast cancer. Eur J Cancer 2008, 44:2760-2765

62. Agahozo MC, Hammerl D, Debets R, Kok M, van Deurzen CHM: Tumor-infiltrating lymphocytes and ductal carcinoma in situ of the breast: friends or foes? Mod Pathol 2018, 31:1012-1025

63. Hannafon BN, Ding WQ: Intercellular communication by exosomederived microRNAs in cancer. Int J Mol Sci 2013, 14:14240-14269

64. King HW, Michael MZ, Gleadle JM: Hypoxic enhancement of exosome release by breast cancer cells. BMC Cancer 2012, 12:421

65. Maji S, Chaudhary P, Akopova I, Nguyen PM, Hare RJ, Gryczynski I, Vishwanatha JK: Exosomal annexin II promotes angiogenesis and breast cancer metastasis. Mol Cancer Res 2017, 15: 93-105

66. Xiao D, Barry S, Kmetz D, Egger M, Pan J, Rai SN, Qu J, McMasters KM, Hao H: Melanoma cell-derived exosomes promote epithelial-mesenchymal transition in primary melanocytes through paracrine/autocrine signaling in the tumor microenvironment. Cancer Lett 2016, 376:318-327

67. Zhang L, Zhang S, Yao J, Lowery FJ, Zhang Q, Huang WC, Li P, Li M, Wang X, Zhang C, Wang H, Ellis K, Cheerathodi M, McCarty JH, Palmieri D, Saunus J, Lakhani S, Huang S, Sahin AA, Aldape KD, Steeg PS, Yu D: Microenvironment-induced PTEN loss by exosomal microRNA primes brain metastasis outgrowth. Nature 2015, 527:100-104

68. Rodriguez M, Silva J, Herrera A, Herrera M, Pena C, Martin P, GilCalderon B, Larriba MJ, Coronado MJ, Soldevilla B, Turrion VS, Provencio M, Sanchez A, Bonilla F, Garcia-Barberan V: Exosomes enriched in stemness/metastatic-related mRNAs promote oncogenic potential in breast cancer. Oncotarget 2015, 6:40575-40587

69. Donnarumma E, Fiore D, Nappa M, Roscigno G, Adamo A, Iaboni M, Russo V, Affinito A, Puoti I, Quintavalle C, Rienzo A, Piscuoglio S, Thomas R, Condorelli G: Cancer-associated fibroblasts release exosomal microRNAs that dictate an aggressive phenotype in breast cancer. Oncotarget 2017, 8:19592-19608

70. Pigati L, Yaddanapudi SC, Iyengar R, Kim DJ, Hearn SA, Danforth D, Hastings ML, Duelli DM: Selective release of microRNA species from normal and malignant mammary epithelial cells. PLoS One 2010, 5:e13515

71. Hannafon BN, Trigoso YD, Calloway CL, Zhao YD, Lum DH, Welm AL, Zhao ZJ, Blick KE, Dooley WC, Ding WQ: Plasma exosome microRNAs are indicative of breast cancer. Breast Cancer Res 2016, 18:90

72. Li Q, Eades G, Yao Y, Zhang Y, Zhou Q: Characterization of a stemlike subpopulation in basal-like ductal carcinoma in situ (DCIS) lesions. J Biol Chem 2014, 289:1303-1312

73. Gernapudi R, Yao Y, Zhang Y, Wolfson B, Roy S, Duru N, Eades G, Yang P, Zhou Q: Targeting exosomes from preadipocytes inhibits preadipocyte to cancer stem cell signaling in early-stage breast cancer. Breast Cancer Res Treat 2015, 150:685-695

74. Gebert LF, Rebhan MA, Crivelli SE, Denzler R, Stoffel M, Hall J: Miravirsen (SPC3649) can inhibit the biogenesis of miR-122. Nucleic Acids Res 2014, 42:609-621

75. Rupaimoole R, Slack FJ: MicroRNA therapeutics: towards a new era for the management of cancer and other diseases. Nat Rev Drug Discov 2017, 16:203-222

76. Chakraborty C, Sharma AR, Sharma G, Doss CGP, Lee SS: Therapeutic miRNA and siRNA: moving from bench to clinic as next generation medicine. Mol Ther Nucleic Acids 2017, 8:132-143

77. Miller AD: Delivery of RNAi therapeutics: work in progress. Expert Rev Med Devices 2013, 10:781-811

78. Hong CA, Nam YS: Functional nanostructures for effective delivery of small interfering RNA therapeutics. Theranostics 2014, 4: $1211-1232$

79. Bouchie A: First microRNA mimic enters clinic. Nat Biotechnol 2013, 31:577

80. Luan X, Sansanaphongpricha K, Myers I, Chen H, Yuan H, Sun D: Engineering exosomes as refined biological nanoplatforms for drug delivery. Acta Pharmacol Sin 2017, 38:754-763 